\title{
A proposed decision-making framework for a national infiltration SuDS map
}

\begin{abstract}
Purpose - The aim of this paper is to describe the decision-making framework and datasets behind a national GIS map that assesses the suitability of the subsurface for infiltration sustainable drainage systems (SuDS). In combination they provide geoenvironmental information on the necessary geological and hydrogeological considerations to facilitate preliminary site assessment.
\end{abstract}

Approach - The national suitability map comprises four parts, each of which considers a geoenvironmental factor essential to SuDS planning, installation and performance. The first three comprise: a) drainage; b) ground stability and c) pollutant attenuation potential. The final map highlights those areas where infiltration may result in negative consequences such as the initiation or exacerbation of flooding or ground instability.

Findings - The application of the suitability map is demonstrated for an urban setting showing its relevance to both planning for wide spatial- and site-scale assessment.

Research implications - The suitability map aims to provide the data necessary for the assessment of subsurface suitability, rather than a recommendation on the type of infiltration system appropriate to the ground conditions. Future research could address this limitation by incorporating the use of quantitative site-scale information, although it is unlikely that this would be possible at a national-scale.

Practical implications - The suitability map is valid for use by developers and planners for the preliminary assessment of sites, but also by unitary authorities for the consideration of planning applications.

Originality - This paper introduces an innovative decision-making framework to enable preliminary site assessment for infiltration SuDS and demonstrates the feasibility of the approach through an urban case study.

Keywords Sustainable drainage, National suitability map, Drainage, Stability, Pollutant attenuation

Paper type Research paper

\section{Introduction}

The urbanization of land results in the replacement of natural ground with impervious surfaces such as pavements, buildings and roads, which require artificial drainage to dispel surface water. Artificial drainage has traditionally been concerned with the rapid removal of surface water downstream. However, as urban areas have expanded, this has resulted in a number of hydrological and biochemical environmental impacts (Faulkner, 2004). Hydrologically, rapid drainage and imperviousness has led to increased flood discharge and flashiness and decreased lag time within and downstream of the urban area (Jacobson, 2011). Impacts include downstream flooding (Swan, 2010), pluvial flooding (Coulthard and Frostlick, 2010), defined as rainfall-generated overland flow unconnected with rivers or sewers, and sewer surcharging. The impacts of urbanization on surface water biochemistry are as a result of contact with point source anthropogenic contamination such as combined sewer overflows (Mulliss et al., 1997) and contaminated land (Shepherd et al., 2006), and also diffuse contamination originating from a wide range of urban sources. 
To mitigate the impacts of urbanization on surface water hydrology, recent changes and additions to both European and UK national legislation is driving the implementation of sustainable drainage systems (SuDS). SuDS differs from traditional piped drainage networks by employing methods that mimic natural drainage, rather than acting purely as a rapid conveyance mechanism. These systems naturalise drainage by passively removing surface water contaminants and naturalising flow rates. Techniques include rainwater harvesting, pollutant pretreatment, water storage and/or infiltration to the ground. By attenuating water volume and pollutants near the source of surface water generation, the rate of flow downstream, flood discharge and flashiness is reduced and water quality is improved. Further significant improvements in water quality are realized as a result of a reduced stormwater flow in sewers which reduces overflow to combined sewers, which often results in discharge of raw sewage to watercourses.

The driving European legislation is focused on using sustainable drainage to meet the targets for water quality set by the EU Water Framework Directive 2000 (EU, 2000). This directive aims to achieve a 'good' ecological and chemical status in all watercourses by 2015 . In Scotland, the Government responded to this legislation by passing the Water Environment (Controlled Activities) (Scotland) Act 2005 (SSI, 2005), which contains a specific requirement for sustainable drainage. The driving legislation in England and Wales is particularly associated with the use of SuDS to reduce surface water flooding. Following catastrophic flooding events across England in 2007, the Government instigated a review of the causes and consequences (Pitt, 2008), which identified that flooding was largely attributable to surface imperviousness and high intensity rainfall. These findings influenced the Government's 'Future Water' strategy for England and Wales (DEFRA, 2008), which resulted in the enactment of the Floods and Water Management Act 2010 (HMSO, 2010) which included the provision for SuDS. The subject of this paper is infiltration-to-the-ground, a technique which is given priority over other SuDS types in the current UK building regulations (HMSO, 2002).

Infiltration-based drainage systems, in the form of engineered soakaways, have been used since at least the early $17^{\text {th }}$ century to attenuate rainwater in built environments. The importance of this technique is unsurprising given that it emulates a process that occurs ubiquitously within the natural landscape as part of the water cycle. The extent of natural infiltration depends largely on the permeability of the underlying geology and therefore the suitability of the ground for artificial infiltration is also dependent on the properties of the subsurface. This is particularly pertinent for infiltration systems, such as soakaways, that focus surface water recharge into an engineered structure that occupies a relatively small area, thereby enhancing infiltration over the natural rate. For this reason, infiltration or soakaway testing should be undertaken before an infiltration system is designed.

The suitability of the ground for infiltration SuDS is not only dependent on the permeability however, the site must also be considered with regards to the hydrogeology, ground stability and potential for pollutant transport. To facilitate the preliminary assessment of subsurface suitability, this paper describes a decision-making framework that can be followed to ensure that the relevant factors are considered. Further, it introduces the concept of a national infiltration SuDS suitability map that aims to provide the information necessary to make a preliminary judgement on the type of system that may be compatible with the surface. 


\section{Decision-making}

Planners, consultants and developers will need to consider the suitability of the subsurface for the installation of infiltration-based drainage systems during the initial site planning process. Early consideration of the SuDS approach is imperative as it will likely determine the site layout and drainage land take requirements. The decision on the suitability of a site for infiltration, is unlikely to be simply 'yes' or 'no'. Instead the outcome will be a list of opportunities and constraints. This is because the compatibility of the subsurface for infiltration is strongly dependent upon the type and design of the infiltration system (Figure 1).
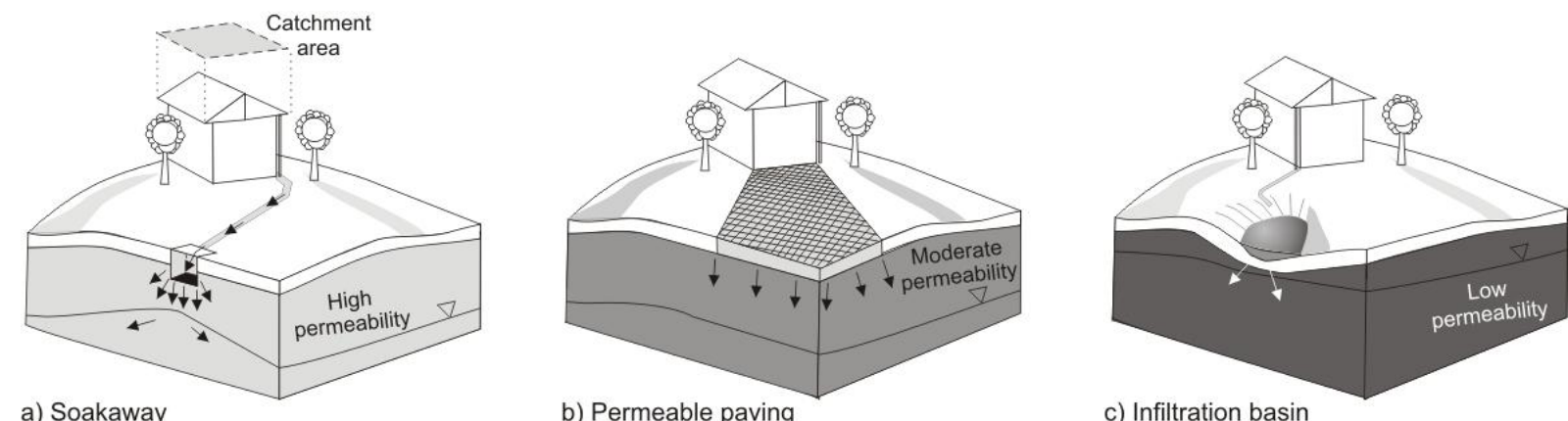

Figure 1. Schematic diagram illustrating different drainage solutions for a roof catchment area underlain by different subsurface conditions.

Three of the common types of infiltration-SuDS are shown in Figure 1. They include a soakaway, a permeable pavement and an infiltration basin. The properties of the subsurface dictate which system is most appropriate. For example, in relatively free-draining ground where the groundwater table is relatively deep, there are minimal design constraints on the type of system installed and hence systems which require good drainage potential, such as soakaways, are commonly installed. On less permeable ground water is less likely to infiltrate as readily and therefore systems need to be designed to allow infiltration over large surface areas (e.g. permeable pavement), or to provide sufficient water storage capacity (e.g. infiltration basins). This is to ensure that the infiltration system will not be overwhelmed.

To guide the decision-maker through the process of compiling and evaluating relevant subsurface data, the BGS have developed a framework to aid preliminary decision-making (Table 1). The framework comprises four steps. The first step eliminates those locations where infiltration is inadvisable because the addition of water to the ground may lead to ground instability or flooding. For all other areas, where infiltration is possible, the remaining steps consider the opportunities and constraints for the type and design of appropriate infiltration systems, with regards to: (i) drainage; (ii) stability, and (iii) groundwater quality.

Table 1. Framework for preliminary decision making on the suitability of the ground for infiltration

\begin{tabular}{|c|c|}
\hline & Factors to consider \\
\hline $\begin{array}{l}\text { Step 1: Considers } \\
\text { whether there are any } \\
\text { significant constraints } \\
\text { that mean an } \\
\text { infiltration system } \\
\text { should not be installed. }\end{array}$ & $\begin{array}{l}\text { - Rocks that have a very significant potential to become unstable } \\
\text { when water is added, for example, rocks that may dissolve, } \\
\text { landslide, collapse or are affected by shallow mining. } \\
\text { - Areas susceptible to groundwater flooding } \\
\text { - Areas covered by artificial ground that has unknown chemical } \\
\text { and physical properties }\end{array}$ \\
\hline
\end{tabular}




\begin{tabular}{|c|c|}
\hline & $\begin{array}{l}\text { Proximity to Environment Agency (EA) groundwater source } \\
\text { protection zones, placed around public supply water boreholes }\end{array}$ \\
\hline $\begin{array}{l}\text { Step 2: Considers the } \\
\text { extent to which the } \\
\text { ground will drain. }\end{array}$ & $\begin{array}{l}\text { - Depth to water table and potential for perched water tables } \\
\text { - Permeability of superficial deposits } \\
\text { - Permeability of underlying bedrock deposits, where superficial } \\
\text { deposits are absent or thin. } \\
\text { - Slope and its impact on subsurface lateral flows }\end{array}$ \\
\hline $\begin{array}{l}\text { Step 3: Considers } \\
\text { whether the addition of } \\
\text { water to the ground } \\
\text { may potentially result } \\
\text { in ground instability. }\end{array}$ & $\begin{array}{l}\text { Instability hazards that may not preclude infiltration, but that } \\
\text { should be considered during the design phase including rocks } \\
\text { and deposits that are potentially susceptible to dissolution, } \\
\text { landslide, running sand, swelling clays, collapse and } \\
\text { compression } \\
\text { - Instability hazards resulting from shallow mining }\end{array}$ \\
\hline $\begin{array}{l}\text { Step 4: Considers } \\
\text { whether the infiltration } \\
\text { of surface water is } \\
\text { likely to impact } \\
\text { groundwater quality. }\end{array}$ & $\begin{array}{l}\text { - Quality of surface water upstream of the infiltration system } \\
\text { - Mobilisation of surface and subsurface contaminants } \\
\text { - Attenuation potential of the unsaturated zone deposits } \\
\text { - Possible pre-treatment requirements } \\
\text { - Proximity to groundwater source protection zones (EA), placed } \\
\text { - } \text { around public supply water boreholes } \\
\text { - Proximity of other groundwater abstractions }\end{array}$ \\
\hline
\end{tabular}

\section{National map}

The aim of the national map is to: (i) guide the user through the relevant subsurface considerations; (ii) provide data necessary for site-specific decision-making, and (iii) provide a spatial overview of infiltration-suitability over wide spatial areas.

The proposed structure of the geographical information system (GIS) approach is shown in Figure 2. The 'decision-making' steps are comparable to those in Table 1. Each step forms a separate section of the GIS methodology and is populated with relevant datasets, held by the British Geological Survey that will facilitate preliminary decision-making. The datasets queried at each stage, are shown in the upper boxes of Figure 2. The majority of datasets have a scale of 1: 50000 and full national UK coverage. It is the intention that the user will be able to download point-based attribute data in the form of a list of qualitative descriptions describing the likely subsurface properties. In addition, a methodology to create three additional 'summary' GIS layers has been developed. These layers show the suitability of the ground for infiltration over larger spatial areas, without requiring the user to consider all underlying datasets. The summary layers include: (i) suitability of the ground to accept water; (ii) stability considerations, and (iii) groundwater quality considerations (lower boxes in Figure 2). The layers will highlight areas that are unsuitable for infiltration, whilst providing qualitative information on the likely extent of design constraints that will be applicable when planning the type of infiltration scheme. The summary layers aggregate the data from the underlying datasets by displaying the areas (polygons) which are attributed with the greatest design constraint. 


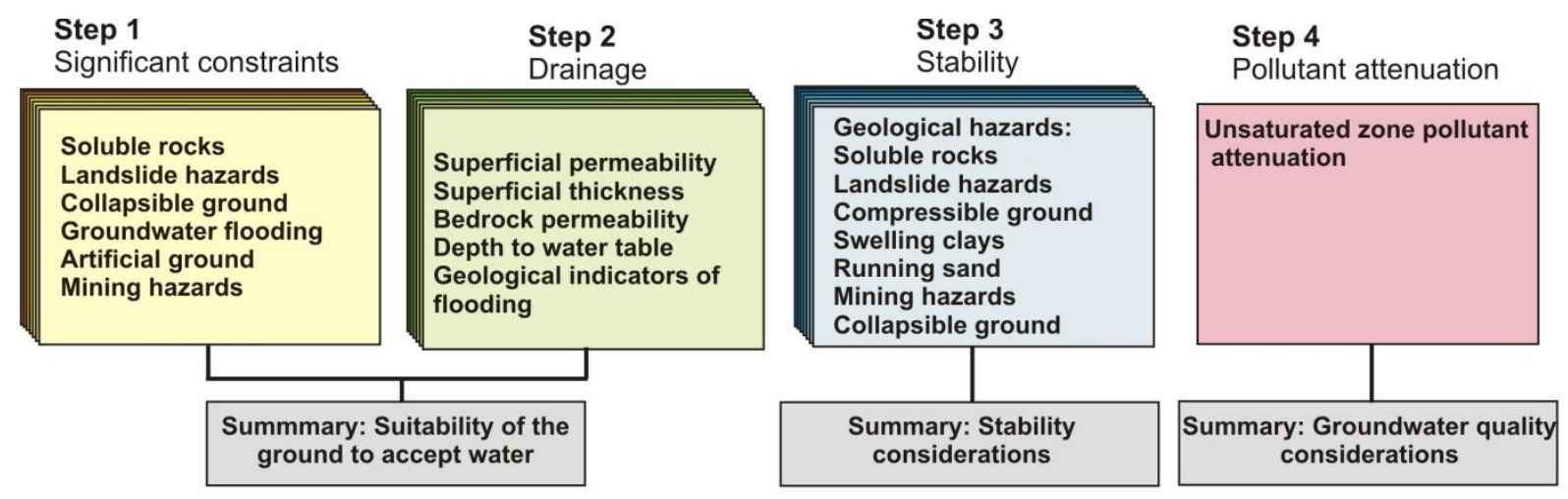

Figure 2. Schematic representation of methodology for the national infiltration-to-the-ground suitability map.

The proposed methodology was implemented over a $7 \mathrm{~km}^{2}$ area of Glasgow. The underlying data layers and the aggregated summary layers are shown in Figure 3.
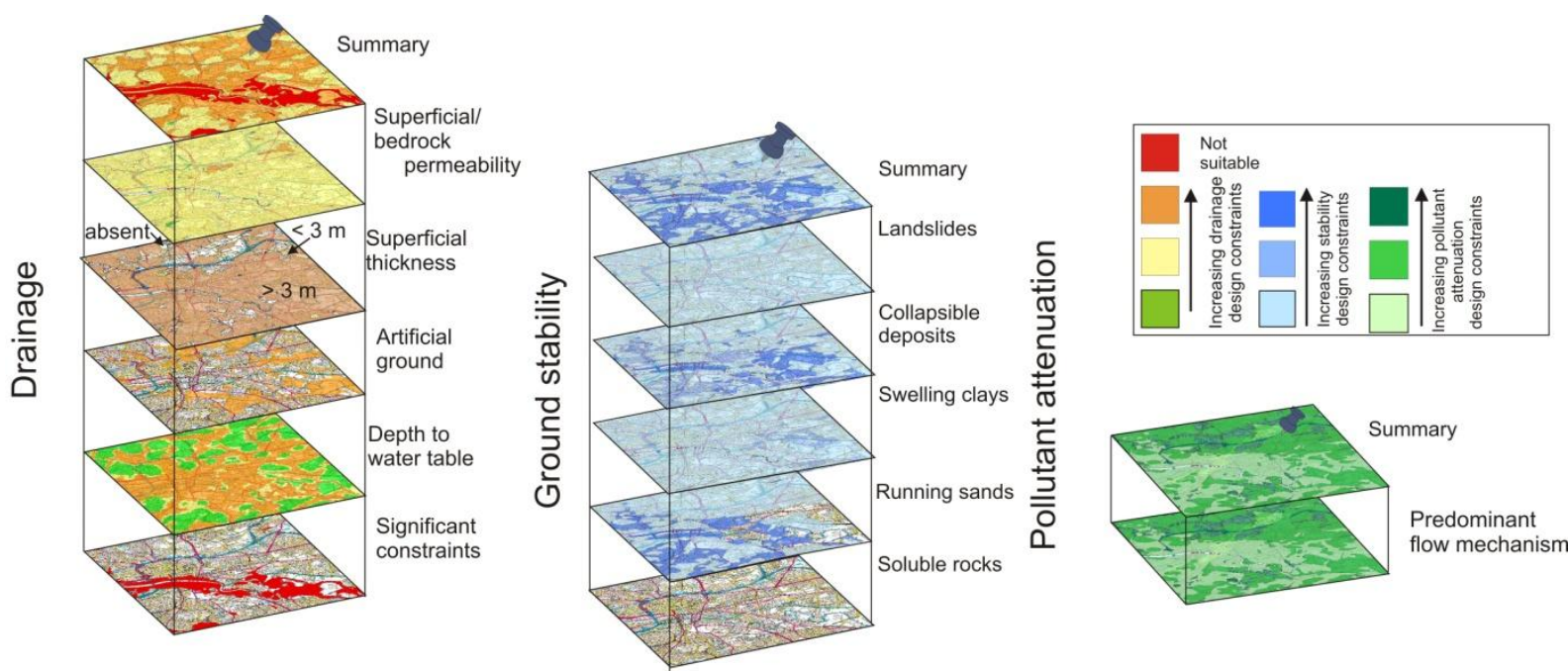

Figure 3. Schematic representation of provisional results for an area of Glasgow. OS topography $\odot$ Crown Copyright. All rights reserved. 100017897/2011

An example location is marked by the pin in Figure 3. The suitability of this location for infiltration is discussed below.

Step 1. Significant constraints: The location is not impacted by significant constraints, such as high susceptibility to groundwater flooding, or the presence of significant ground instability and therefore it is deemed suitable for infiltration.

Step 2. Drainage: The location is underlain by superficial deposits comprising Devensian Till that characteristically has a permeability that varies spatially between low and high. The superficial deposits are more than $3 \mathrm{~m}$ thick and hence the permeability of the bedrock does not need to be considered. The depth to the water table from the ground surface is likely to be more than $5 \mathrm{~m}$, indicating that the unsaturated zone will accommodate temporary rises in groundwater level associated with storm events, whilst still providing sufficient unsaturated zone thickness for attenuation processes.

Step 3. Stability: The subsurface deposits underlying the site are not significantly impacted by hazards associated with landslides, collapsible deposits, swelling clays, running sands or soluble rocks.

Step 4. Pollutant attenuation: The predominant flow mechanism in the superficial deposits is through fractures in the till. Pollutant attenuation is therefore likely to be minimal as 
percolating water will have a short residence time, allowing only minimal interaction with particle surfaces before it reaches the groundwater. To prevent deterioration in groundwater quality, the installation of pre-treatment stages upstream of the infiltration system should be considered.

Summary: Given the variable permeability of the superficial deposits, an infiltration system that incorporates either a large surface area for infiltration or a water storage component (e.g. an infiltration basin) is likely to be most applicable. Infiltration testing is always necessary to confirm the drainage properties of the ground and will determine whether the drainage potential at the site lies on the low or high end of the stated range. Infiltration to the ground is unlikely to impact ground stability. Attenuation of pollutants in the unsaturated zone is likely to be minimal, so the installation of pre-treatment stages should be considered.

\section{Conclusions}

This paper presents a four-step framework that can be used, by drainage professionals, planners and regulators to form preliminary decisions on the suitability of the subsurface for the installation of infiltration-based SuDS. In addition, it proposes a methodology for a national GIS map that will provide users with a wealth of data that are relevant to subsurface suitability both prior to, and alongside the planning and design of infiltration systems. The BGS are currently implementing this methodology to create a national infiltration suitability map. For updated information visit: www.bgs.ac.uk/suds.

\section{Acknowledgements}

This paper is published with the permission of the Executive Director of the British Geological Survey (NERC).

COULTHARD, T. \& FROSTLICK, L. (2010). The Hull floods of 2007: implications for the governance and management of urban drainage systems. Journal of Flood Risk Management, 3, 223-231.

DEFRA (2008). Future Water: The Government's water strategy for England. London: H M Government.

EU (2000). Directive 2000/60/EC of the European Parliament and of the Council of 23 October 2000 establishing a framework for community action in the field of water policy. In: COUNCIL, E. P. A. (ed.) 22 December 2000 ed.

FAULKNER, S. (2004). Urbanization impacts on the structure and function of forested wetlands. Urban Ecosystems, 7, 89-106.

HMSO (2002). The building regulations 2000: Approved document $H$ - Drainage and waste disposal. Office of the Deputy Prime Minister.

HMSO (2010). Floods and Water Management Act, Chapter 29. HM Government, Her Majesty's Stationery Office.

JACOBSON, C. (2011). Identification and quantification of the hydrological impacts of imperviousness in urban catchments: A review. Journal of Environmental Management, 92, 1438-1448.

MULLISS, R., REVITT, D. \& SHUTES, R. (1997). The impacts of discharges from two combined sewer overflows on the water quality of an urban watercourse. Water Science and Technology, 36, 195-199.

PITT, M. (2008). Pitt Review: Learning lessons from the 2007 floods. HM Government. 
SHEPHERD, K., ELLIS, P. \& RIVETT, M. (2006). Integrated understanding of urban land, groundwater, baseflow and surface-water quality - The City of Birmingham, UK. Science of the total environment, 360, 180-195.

SSI (2005). No. 348, Environmental Protection Water, The Water Environment (controlled activities) (Scotland) Regulations 2005. Scottish Statutory Instruments.

SWAN, A. (2010). How increased urbanisation has induced flooding problems in the UK: A lesson for African cities? Physics and chemistry of the earth, 35, 643-647. 